\title{
The government coordination mechanism research on the coordinated development of Beijing-Tianjin-Hebei manufacturing
}

\author{
Chen Wei \\ College of Economics and Management, Hebei \\ University of Science and Technology \\ Shijiazhuang,P.R China \\ e-mail: chenwei0123@126.com
}

\author{
Ma Jiao \\ College of Economics and Management, Hebei \\ University of Science and Technology \\ Shijiazhuang,P.R China \\ e-mail: maxiaojiaoz@126.com
}

\begin{abstract}
The cooperation of Beijing-Tianjin-Hebei government is very important to the coordinated development of Beijing-Tianjin-Hebei manufacturing, and is of great significance for promoting the development of regional economic integration of the Beijing-Tianjin-Hebei region. Combined with the characteristics of the coordinated development of manufacturing industry of the BeijingTianjin-Hebei region, using the game theory analysis method, this paper expounds the necessity of Beijing-Tianjin-Hebei government cooperation. Based on it, the paper put forward reasonable suggestions to the onstruction of Beijing-TianjinHebei government coordination mechanisms
\end{abstract}

Keywords-Beijing-Tianjin-Hebei manufacturing; Coordinated development; The government coordination mechanism; Game theory

\section{INTRODUCTION}

The coordinated development of Beijing-Tianjin-Hebei manufacturing is an important part of the development of regional economic integration, but the current government cooperation of Beijing-Tianjin-Hebei tripartite has many problems, which seriously restricted the three coordinated development of manufacturing industry. Therefore, it is urgently needs to establish the government coordination mechanism for the academia and the government.

Foreign scholar Agranoff and Robert believe that political factors, the government operation, fiscal and tax aspects have a great influence on cross-regional cooperation between the government, through the analysis of the British local cross-regional cooperation. And through the establishment of feasible cooperation mechanism, a collaborative development organization, even with the model of "corporate governance", can promote the government cooperation [1]. Domestic scholar $\mathrm{Lu}$ Yao analysesd the relationship between the development of the urban agglomeration and coordination mechanism establishment of the government, as Yangtze river delta and pearl river delta urban agglomeration for example, points out that the coordination and cooperation of each city local government plays a vital role for the healthy development of the urban agglomeration [2]. Wang xue-dong, Yang jun discussed the construction of government coordination mechanism during the regional development both at home and abroad, and think that we can draw lessons from the experience of it to the future regional economic coordinated development of China [3]. Wang Xiaozeng, Long chaoshuang think the governmentled, and the establishment of official and unofficial effective cooperation, mutual promotion of wuhan circle cities government coordination mechanism is of great significance to improve the level of wuhan circle cities development, by the research of the government cooperation coordination mechanism of wuhan city circle cities [4]. Bing xing-guo is based on the basic theory of regional economy and combining with the characteristics of Beijing-Tianjin-Hebei regional economic analysis, think that Beijing-Tianjin-Hebei government cooperation is a new growth pole to promote the economic development, and expounds the necessity of establishing government coordination mechanism of the Beijing-Tianjin-Hebei region [5]. Both foreign and domestic research about government coordination mechanism provide a reference basis for the upcoming paper, but there is still a lack of government coordination mechanism research for the coordinated development of Beijing-Tianjin-Hebei manufacturing at present.Combining with the characteristics of the coordinated development of manufacturing industry of the Beijing-Tianjin-Hebei region, using the game theory analysis method,this paper demonstrates the necessity and feasibility of government coordination mechanism to establish, and put forward reasonable suggestions to the building of Beijing-TianjinHebei government coordination mechanism.

\section{ANALYSIS OF THE COORDINATED DEVELOPMENT STATUS OF BEIJING-TIANJIN-HEBEI INDUSTRY}

In the process of the development of regional economic integration, the coordinated development of manufacturing is key link.After years of development, Beijing-TianjinHebei collaboration in manufacturing is mainly two aspects: one is the high and new technology industry begun to take shape along the jingjintang highway, formed a prototype of the new economic belt whichi mainly as high and new technology industries and modern manufacturing industry as the leading factors; The second is the industrial gradient shift is underway across the region, part of the industry chain is forming.Some of Beijing's traditional heavy industries such as steel, the traditional manufacturing industry is gradually transferred to Hebei.In the same time, the automobile and parts of 
electronic information industry of Beijing and Tianjin serving for this administrative region , also provide products and services to the enterprises of adjacent region, but the industrial gradient transfer across the region has not yet in full swing [6]. Visibly, coordinated development of the Beijing-TianjinHebei manufacturing have exchanged from simple materials to the technology capital joint and optimizing the resource configuration, and the coordinated development has the initial results. But in the true sense of the collaborative development ,there should also be equipped with the three basic conditions: The first is the level of manufacturing industry development of the three cities should be adapted to the strength of the regional ecological environment; Second is there should be formed division of labor and cooperation on the three places manufacturing, and each city should have a reasonable city function orientation; The third is there should be perfect benefit coordination mechanism between the three cities, which can garantee the reasonable distribution of the security benefits, and make the coordinated development of Beijing-Tianjin-Hebei manufacturing continue to be healthy. Obviously, there are some concrete problems need to be solved. If the coordinated development of BeijingTianjin-Hebei industry need further in depth.

\section{A. Manufacturing industry transfer shift into "low gradient trap"}

"Low gradient trap" refers to a phenomenon that the area whose industrial structure and technical structure in the innovation and development phase, will transfer the recession, backward industry, technology and product to relatively underdeveloped areas.In the process of BeijingTianjin-Hebei manufacturing industry transfer, Hebei undertaking some of the industry of Beijing and Tianjin, is often sacrifice environmental quality in order to gain.Because of the geographical factors and long traditional manufacturing scale development, environment problem in Hebei area was very serious.In the winter of 2013, a haze weather hit more than half China, Handan Wuan of Hebei provence was almost all shrouded in smoke, and the main reason is there brought together many of steel, coke, cement, electric power, building materials enterprises. High pollution emissions of carbon dioxide, sulfur dioxide, smoke and dust is the main source of fog [7].But as a result of productivity and technical level is relatively backward in Hebei province, the capital stock is relatively small, poor material basis, self-development capacity is weak, in the process of manufacture industry transfer Hebei is in a passive position. The development of Beijing and Tianjin are relatively more priority to the development of Hebei, the ecological resources and environment has been seriously deteriorated, and they are unsustainable for economic development. So they tend to transfer the polluting enterprises to Hebei in the coordinated development of Beijing-Tianjin-Hebei manufacturing process. And Hebei province want to pursuit local economy growth, only at the expense of the environment and resources, then the results fall into the "low gradient trap", making the already fragile ecological environment problem is more serious.From the long-term interests and the interests of the global view, thus industry transfer is detrimental for the coordinated development of
Beijing-Tianjin-Hebei manufacturing, and" low gradient trap" will be severely restricts the development of Hebei power, and further deteriorated environment problems will quickly spread throughout the Beijing-Tianjin-Hebei region.

\section{B. Administrative division lead to regional barriers, and city function orientation is not reasonable}

Beijing-Tianjin-Hebei region has a natural connection on the geographical position, and after accumulation of historical development, It has already have the advantage of collaborative development in planning and resource allocation of the manufacturing industry.But being longterm influenced by administrative division, three government shortsightedness and narrow ruling idea, the development of collaborative manufacturing is severely hindered. Lacking of effective communication and global interests, intensified the competition of interest conflicts and limited resources among them. Especially between Beijing and Tianjin, economic competition motivation is intensive, hampering the complementary cooperation development, making serious convergence of industrial structure, and city function orientation being not clear. For example, Beijing and Tianjin both regarded the electronic information, biological technology and modern medicine, new energy, environmental protection, new materials, advanced manufacturing technology, modern agriculture as the key point of the development of the industry field, leading to regional redundant construction, industry being similar, wasting resources and so on [8].

\section{Lack effective interest coordination mechanism, and they can not share interests}

In the process of coordinated development of BeijingTianjin-Hebei manufacturing, the three parties administrative divisions determined that, the three parties can not put the interests of the whole area as the action target in formulating government policy, appearing the tendency of "instead of", "only emphasizes the self development,does not allow others to develop" [9].Without an effective interests coordination mechanism ,there is no possiblity to realize the unified planning, leading to the development of the manufacturing industry in BeijingTianjin-Hebei unable to realize the complementary advantages, rational allocation of resources, pattern of the free flow of production factors, causing resource waste, malignant competition, and they cannot guarantee benefit sharing. Therefore, the establishment of the interest coordination mechanism among them is necessary to effectively solve the problem of coordinated development of the Beijing-Tianjin-Hebei manufacturing.

Through the above analysis, there still exist many deep-seated problems in the coordinated development of Beijing-Tianjin-Hebei manufacturing. The establishment of government coordination mechanism is necessary. This paper will use the game theory to analysis the contradictions in the process of competition and cooperation among the three parties, providing a reference for the establishment of Beijing-Tianjin-Hebei coordination mechanism. 
III. THE GOVERNMENT COOPERATIVE GAME ANALYSIS OF THE COORDINATED DEVELOPMENT OF BEIJING-TIANJINHEBEI MANUFACTURING

\section{A. The"prisoner's dilemma" in the coordinated development of Beijing-Tianjin-Hebei manufacturing}

The basic content of the game theory including game players, game strategy and benefits.Government agencies of the Beijing, Tianjin an Hebei are the body of benefit, which are assumpted as the "rational man".Various policies are assumpted as the game strategy.

Beijing,Tianjin and Hebei are in cooperation and noncooperation game between their respective, we assume both sides reap the benefits of cooperation $\mathrm{R}$ unit, $\mathrm{P}$ unit yield not cooperation. When one party cooperate but the other party do not cooperate, then the cooperated party will be dishonest and get only $\mathrm{S}$ unit revenues, and the uncooperative party get $\mathrm{T}$ unit revenues. What is more, $\mathrm{T}>$ $\mathrm{R}>\mathrm{P}>\mathrm{S} ; \mathrm{R}<\mathrm{S}+\mathrm{T} / 2$.All policy portfolio pay-off matrix are in table 1.The rows and columns in the table represent all the strategies in A and B area.

TABLE I. PAY-OFF MATRIX

\begin{tabular}{cccc} 
& \multicolumn{3}{c}{ Area B } \\
\cline { 3 - 3 } & & cooperation & noncooperation \\
\cline { 3 - 4 } Area & cooperation & $\mathrm{R}, \mathrm{R}$ & $\mathrm{S}, \mathrm{T}$ \\
\cline { 3 - 4 } $\mathrm{A}$ & noncooperation & $\mathrm{T}, \mathrm{S}$ & $\mathrm{P}, \mathrm{P}$ \\
\cline { 3 - 4 } & & &
\end{tabular}

Game players are "rational man", and "all participants are rational person" is the consensus of both sides. Then the game players will choose its strategy on the assumption that the other party will choose their best strategy. Any party of the game participants choose cooperation, then it will face the risk of loss earnings if another party chooses noncooperation. If choose noncooperation, he, at least,can ensure existing revenue without loss. It is called the "dominant strategy" that whatever strategy rival chooses, he always choose his own best competition strategy.Through the above analysis, the game's dominant strategy is noncooperation.Then (noncooperation, noncooperation) is the Nash equilibrium of the game, and both sides of the game achieve revenue balance.And under the existing condition, both parties do not intend to change their strategy, which is a game of "prisoner's dilemma"."Prisoner's dilemma" is a typical case of noncooperative game, and it reveals the contradiction between individual rationality and collective rationality during the game strategy choosing [10]

\section{B. The dynamic equilibrium of government's game between Beijing,Tianjin and Hebei}

The "prisoner's dilemma" model has its conditions of use: the first one is the cooperation premise between both sides is no constraints or agreement and strict restrictions between the three governments, so that the three governments pursuit his own interests, and is regardless of the other parts; The second one is that, the game of them is one-time static game, which is the three parties eventually choose their own dominant strategy (noncooperation, noncooperation), then stop the game. However, the cooperation between the governments might not have been no binding agreements, terms or conditions, and the country's regional planning may only be only one negotiation, and the game is regular activities.So, being out of the "prisoner's dilemma" for achieving tripartite cooperation, is not impossible.

Assume that the game between the governments is an infinitely repeated game, then first of all,it is to be sure that the result of the game will be a lot of possibilities. At first both sides of the game can test cooperation, once found the other choose noncooperation then he is also choose noncooperation as revenge, which is called "trigger strategy".Trigger strategy is the key mechanism to implement cooperation and improve the efficiency of balancing in repeated games [11].To make the analysis simple, we can assume that $\mathrm{R}=2, \mathrm{P}=1, \mathrm{~T}=3, \mathrm{~S}=0$, namely that if area $\mathrm{A}$ and $\mathrm{B}$ choose cooperation, the benefit is 2 units; if they choose noncooperation, income will be 1 unit;if one party choose cooperation well the other party choose noncooperation, then the cooperative party will gain 0 , and the uncooperative party will gain 3.The pay off matrix is the table 2 .

TABLE II. PAY-OFF MATRIX 2

Area B

\begin{tabular}{|c|c|c|c|}
\hline \multirow{3}{*}{ Area } & \multirow{3}{*}{$\begin{array}{c}\text { cooperation } \\
\text { noncooperation }\end{array}$} & cooperation & noncooperation \\
\hline & & 2,2 & 0,3 \\
\hline & & 3,0 & 1,1 \\
\hline
\end{tabular}

Obviously, a single game Nash equilibrium is (noncooperation, noncooperation), but it is not pareto efficiency optimal strategy combination, with the benefits of (cooperation, cooperation) strategy combinations $(2,2)$ is more than $(1,1)$.And limited times repeated game can't achieve Nash equilibrium (cooperation, cooperation), because when using reverse induction to analyze repeated twice game, we can obviously get that the second phase is still a prisoner's dilemma for both sides.So, no matter how the result of the previous game was, the Nash equilibriumthe of the second stage is still (noncooperation, noncooperation) strategy combinations.Assume that the game is infinitely repeated, and both sides of the game use the trigger strategy: in the first place : One of the players is trying to choose cooperation, if the other party also choose cooperation strategy, then the first party will adhere to choose cooperation in later stages. Once found other parties choose noncooperation, then will never choose cooperation in retaliation. So (cooperation, cooperation) is the Nash equilibrium of infinite times repeat games.The following is the reasoning:

Due to appearing different strategies to (cooperation, cooperation) at any stage in the later, the area A will never choose cooperation, and area B will also always choose noncooperation, namely that the second part of the best response strategy of area $\mathrm{B}$ to the trigger strategy of area A is consistent. What strategic area B choose in the first stage become the key problem.Assuming that the discount coefficient for the future earnings is $\delta$, if area B choose noncooperation, gain 3 unite in the first phase, but causiong area A choose noncooperation as revenge, and as a result area B's earning will be 1 unite for ever. The gross income present value is :

$$
\pi_{1}=3+1 g \delta+1 g \delta^{2}+1 g \delta^{3}+\cdots=3+\frac{\delta}{1-\delta}
$$

If area $\mathrm{B}$ choose cooperation, then the earning in the first stage is 2 , and in the future infinite repeated game 
stages will have been to choose cooperation.Total income present value is $\pi_{2}$, and because the gross income present value of starting from the second phase of infinite repeated game and from the first stage can be considered as equal, so when its total income present value converted into earnings for the first stage, it will be $\delta \mathrm{g} \pi_{2}$, thus the total income present value of the infinite times repeat games is:

$$
\pi_{2}=\frac{2}{1-\delta}
$$

So when $\frac{2}{1-\delta}>3+\frac{\delta}{1-\delta}$, namely $\delta>1 / 2$, area $\mathrm{B}$ will choose cooperation strategy, or else he will choose noncooperation strategy. Due to that the infinite times repeat games of starting from the second stage and from the first stage of are exactly the same, then area B in the second stage also inevitable choose cooperation. And so on, only if area A choose trigger strategy, area B will always choose cooperation strategy.Area A at first, of course, also can choose noncooperation, so area B will also choose noncooperation to retaliate, thus achieve Nash equilibrium (noncooperation, noncooperation). But the latter yields are much smaller than the former, so the reasonable choice is trigger strategy rather than adhering to the "prisoner's dilemma".

\section{CONCLUSIONS}

Based on the above theory analysis, the region $\mathrm{A}$ and $\mathrm{B}$ can achieve Nash equilibrium (cooperation, cooperation) in infinitely repeated game. In reality, if Beijing, Tianjin and Hebei tend to carry on the long-term cooperation, to make the coordinated development of manufacturing industry keep on, they should satisfy the following conditions: Firstly, the game between the governments is unlimited.Obviously, "prisoner's dilemma" is just a one-off game, then the parties based on their respective benefit maximization, could reach noncooperative Nash equilibrium.If be unlimitied repeated game, "prisoner's dilemma" is likely to crack, then both sides may occur respective cooperation Nash equilibrium, thus formed continued cooperation.Secondly, Beijing,Tianjin and Hebei should set a binding agreement. Premise hypothesis of cooperative game between the participants is to reach a binding agreement, restricting unfair and unjust duriong its interaction. Increasing the cost of betrayal can reduce the revenue of noncooperative local government, and raise the possibility of cooperation. Thirdly, the cooperation between Beijing,Tianjin and Hebei is indefinitely.Considering either of the game participants will likely take the breach in the last game, to maximize his own interest and make other areas loss, so that this expectation will make other participants choose noncooperation before the last cooperation, and so on, then the initial cooperation will not succeed.If cooperation is indefinitely, Beijing, Tianjin and Hebei will hope for the future long-term interests which will motivate tripartite cooperation strategy.

\section{ACKNOWLEDGMENT}

The research work was supported by Science and Technology Agency Foundation of Hebei Provincial under Grant No. 15214705D..

\section{REFERENCES}

[1] Agranoff and Robert, "Directions in Intergovernmental Management", International journal of Public Administration, vol. 4, Nov. 1988, pp. 357-391.

[2] Lu Yao, "The development of urban agglomeration and government coordination mechanism — take Yangtze river delta and pearl river delta urban agglomeration for example", Journal of southwest traffic university (social and science edition), vol. 12, 2006.

[3] Wang Xue-dong and Yang jun. "Regional development of government coordination mechanisms construction experience and reference both at home and abroad", Science and management, vol. 5, 2013.

[4] Wang Xiaozeng and Long Chaoshuang, "Government cooperation coordination mechanism research based on the wuhan city circle", Journal of hubei academy of social sciences, vol. 1, 2007.

[5] Bing Xing-guo, "Study of government coordination mechanism of the Beijing-Tianjin-Hebei regional economic cooperation", Journal of bohai sea economic outlook, vol.7, 2011.

[6] Ma Hailong, "History, present situation and the future: talk about Beijing-Tianjin-Hebei region cooperation". Journal of economist, vol, 5, 2009..

[7] Lanzhou university publication: Industrial linkage of cross-regional coordination mechanism research., 2014

[8] An Shu-wei and Zhang Su-e, "Industrial chain and the development of manufacturing in Beijing-Tianjin-Hebei", Friends of the leadership, vol, 4, 2001.

[9] Li Suxi and Qang xp. "Cooperative game analysis of BeijingTianjin-Hebei service and mechanism design". Journal of business research, vol. 1, 2008

[10] Shanghai: Shanghai people's publishing house: Game theory and information economics, Zhang Weiying.,2004.

[11] Shanghai: fudan university press, Economic game theory, Xie Shiyu ,2007. 